\title{
Optimizing Mineral Nutrition for Flower Production in Heliconia 'Golden Torch' Using Response Surface Methodology
}

\author{
John Clemens ${ }^{1}$ and R. Hugh Morton ${ }^{2}$ \\ Massey University, Private Bag 11 222, Palmerston North, New Zealand
}

\begin{abstract}
AdDitional INDEX words. irradiance, flowering, fertilization
Abstract. Containerized plants of Heliconia psittacorum L.f. x H. spathocircinata Aristeguieta 'Golden Torch' were grown in a greenhouse for 8 months from early summer to winter under selected combinations of $\mathbf{N}, \mathbf{P}$, and K. Fertilizer rates ranged from zero to rates that exceeded those reported in the literature by $50 \%$ to $100 \%$. Biomass variables (vegetative and inflorescence dry weight, and leaf area) were predicted to be maximized at high $N$ and high $N$ to $P$, and $\mathrm{N}$ to $\mathrm{K}$ ratios corresponding to $\mathrm{N}-\mathrm{P}-\mathrm{K}$ application rates of $1.2,0.5$, and $0.6 \mathrm{~kg} \cdot \mathrm{m}^{-3}$, respectively $(\approx 2: 1: 1)$. However, the number of shoots and flowers produced per rhizome were maximal at lower $N$ to $K$ ratios $(1: 1)$. Flower yield could therefore be optimized with appropriate fertilization, provided attention was paid to the $\mathbf{N}$ to $\mathrm{K}$ ratio so that the size of plants and their flowers was not compromised by efforts to increase shoot and flower number. The heavier the rhizome planted, the shorter the time for shoot emergence and flowering to occur, and the greater the number of flowers harvested. However, rhizome weight had no effect on number of shoots to emerge. The probability of shoots flowering declined markedly with order of shoot emergence, although this could be increased with appropriate mineral nutrition. The maximum number of leaves subtending the inflorescence (seven) was obtained at high $\mathrm{N}$ and $\mathrm{P}$ rates. Flower production was probably limited by declining solar radiation in autumn, and by within-plant competition for rooting space.
\end{abstract}

The genus Heliconia L. (lobster-claw or false bird-of-paradise) has attracted much attention for its floricultural potential as a source of cut flowers and flowering pot plants. In general, the culture of several cultivars and species grown outdoors in the warmer part of the United States and the Caribbean is well understood (Criley and Broschat, 1992). The potential of Heliconia sp. as an indoor crop has only been explored in Europe (Geertsen, 1989; van Raalte and van Raalte-Wichers, 1973).

Relative to other floricultural crops, Heliconia sp. in cultivation generally require high rates of macroelements, particularly $\mathrm{N}$ (Criley and Broschat, 1992). An 18:6:12 NPK fertilizer applied at $3 \mathrm{~kg} \cdot \mathrm{m}^{-2} \cdot \mathrm{year}^{-1}$ was recommended for $H$. psittacorum 'Andromeda' and H. x 'Golden Torch' (Broschat and Donselman, 1983a; Broschat et al., 1984). These authors found that lower fertilizer rates resulted in reduced flower yield under full sun conditions. There was no effect of fertilizer rate under low irradiance $(63 \%$ shade), when yield was reduced substantially. Heliconia sp. are reported to be grown commercially using ratios of $\mathrm{N}, \mathrm{P}$, and $\mathrm{K}$ that include 1:1:1, 1:2:2, 3:1:2, and 3:1:5 (Ball, 1986; Criley, 1990). Van Raalte and van Raalte-Wichers (1973) recommended a ratio of $1 \mathrm{~N}: 2 \mathrm{~K}$. Broschat and Donselman (1987) investigated $\mathrm{N}$ to $\mathrm{K}$ ratios in $H$. psittacorum and reported that $\mathrm{K}$ was not a limiting factor at $\mathrm{K}$ application rates in the range 0.0 to $0.65 \mathrm{~kg} \cdot \mathrm{m}^{-2} \cdot \mathrm{year}^{-1}$. The effects that individual rates and ratios of N, $\mathrm{P}$, and $\mathrm{K}$ have on specific aspects of growth and flowering in Heliconia have not been studied comprehensively. In addition, little published research is available on fertilizer requirements of potted Heliconia sp. (Criley and Broschat, 1992; van Raalte and van RaalteWichers, 1973).

Our first objective was to study the effects of experimental

Received for publication 24 Nov. 1998. Accepted for publication 22 June 1999. The scientific and technical assistance of I.R. Brooking and A.J. Rodgers, respectively, are gratefully acknowledged. The cost of publishing this paper was defrayed in part by the payment of page charges. Under postal regulations, this paper therefore must be hereby marked advertisement solely to indicate this fact. ${ }^{1}$ Institute of Molecular BioSciences.

${ }^{2}$ Associate Professor, Food, Nutrition and Human Health Research Institute. combinations of $\mathrm{N}, \mathrm{P}$, and $\mathrm{K}$ on Heliconia psittacorum L.f. $\mathrm{x} H$. spathocircinata Aristeguieta 'Golden Torch' in order to determine if low $\mathrm{N}$ to $\mathrm{K}$ ratio would enhance flower yield under greenhouse conditions in New Zealand. Because it was not possible to anticipate how absolute and relative rates of $\mathrm{N}, \mathrm{P}$, and $\mathrm{K}$ would affect production or other growth variables, a central composite experimental design was used to explore combinations of these three mineral nutrients, with supply rates that exceeded by $50 \%$ to $100 \%$ any reported in the literature. Secondly, we wished to determine how response to mineral nutrition would be affected by rhizome weight. Our third objective was to establish that irradiance during the New Zealand summer and

Table 1. Scaled treatment combinations for the central composite design and corresponding application rates of $\mathrm{N}, \mathrm{P}$, and $\mathrm{K}$ applied to Heliconia 'Golden Torch'.

\begin{tabular}{lccccc}
\hline \hline & & & & \multicolumn{3}{c}{$\begin{array}{c}\text { Application } \\
\text { rates } \\
\left(\mathrm{Ng} \cdot \mathrm{m}^{-3}\right)\end{array}$} \\
\cline { 5 - 6 } & $\begin{array}{c}\text { Scaled } \\
\text { treatments }\end{array}$ & & & $\mathrm{P}$ & $\mathrm{K}$ \\
\hline $\mathrm{N}$ & $\mathrm{P}$ & $\mathrm{K}$ & $\mathrm{N}$ & 0.2 & 0.25 \\
\hline-1 & -1 & -1 & 0.3 & 0.2 & 0.25 \\
1 & -1 & -1 & 0.9 & 0.6 & 0.25 \\
-1 & 1 & -1 & 0.3 & 0.6 & 0.25 \\
1 & 1 & -1 & 0.9 & 0.2 & 0.75 \\
-1 & -1 & 1 & 0.3 & 0.2 & 0.75 \\
1 & -1 & 1 & 0.9 & 0.6 & 0.75 \\
-1 & 1 & 1 & 0.3 & 0.6 & 0.75 \\
1 & 1 & 1 & 0.9 & 0.4 & 0.5 \\
0 & 0 & 0 & 0.6 & 0.4 & 0.5 \\
0 & 0 & 0 & 0.6 & 0.4 & 0.5 \\
-2 & 0 & 0 & 0 & 0.4 & 0.5 \\
2 & 0 & 0 & 1.2 & 0.5 & 0.5 \\
0 & -2 & 0 & 0.6 & 0.8 & 0.5 \\
0 & 2 & 0 & 0.6 & 0.4 & 0 \\
0 & 0 & -2 & 0.6 & 0.4 & 1.0 \\
0 & 0 & 2 & 0.6 & & \\
\hline
\end{tabular}


Table 2. Main effects of $\mathrm{N}$ and rhizome size on observed times from planting to first shoot emergence (mean $\pm \mathrm{SE}$ ) in Heliconia 'Golden Torch'.

\begin{tabular}{lccc}
\hline $\begin{array}{l}\text { N level } \\
\left(\mathrm{kg} \cdot \mathrm{m}^{-3}\right)\end{array}$ & $\begin{array}{c}\text { Time to } \\
\text { emergence } \\
(\mathrm{d})\end{array}$ & $\begin{array}{c}\text { Time to } \\
\text { Rhizome } \\
\text { size }^{\mathrm{z}}\end{array}$ & $\begin{array}{c}\text { emergence } \\
(\mathrm{d})\end{array}$ \\
\hline $0.0 ; \mathrm{n}=12$ & $37.0 \pm 5.8$ & $2 ; \mathrm{l}$ (largest); $=48$ & $29.9 \pm 1.9$ \\
$0.3 ; \mathrm{n}=48$ & $34.3 \pm 2.1$ & $3 ; \mathrm{n}=48$ & $37.8 \pm 1.8$ \\
$0.6 ; \mathrm{n}=72$ & $34.5 \pm 1.5$ & $4($ smallest $) ; \mathrm{n}=48$ \\
$0.9 ; \mathrm{n}=48$ & $30.4 \pm 1.8$ & & $40.8 \pm 1.6$ \\
$1.2 ; \mathrm{n}=12$ & $28.0 \pm 3.1$ &
\end{tabular}

${ }^{\mathrm{z}}$ Rhizomes size classes corresponded to $\approx 60,45,30$, and $15 \mathrm{~g}$ fresh weight.

autumn would be sufficient (even under greenhouse conditions) for the high rates of fertilization recommended by Broschat et al. (1984) to enhance flower yield.

\section{Materials and Methods}

All experimentation was carried out under natural photoperiod and irradiance in an aluminium-framed greenhouse (maintained at minimum $21{ }^{\circ} \mathrm{C}$ nights, venting at $27{ }^{\circ} \mathrm{C}$ during the day) at Massey University, Palmerston North, New Zealand. The greenhouse covering was a single layer of $150 \mu \mathrm{m}$ polyethylene (Agpac Plastics Ltd, Christchurch, New Zealand) which transmitted 93\% of incident light. In early summer (27 Nov. 1991), 18-month-old clumps of Heliconia psittacorum L.f. x $H$. spathocircinata Aristeguieta 'Golden Torch' (referred to below as Heliconia 'Golden Torch') were separated by hand into divisions, each comprising a length of rhizome (20 to $50 \mathrm{~mm}$ long) and a single pseudostem (referred to below as a shoot) with three to six expanding leaves, and emerging axillary rhizome buds. Based on number of expanding leaves and length of rhizome, divisions were graded into four rhizome weight classes $(\approx 15,30,45$, and 60 $\mathrm{g}$ fresh weight after trimming leaves to a length of $100 \mathrm{~mm}$ measured from the base of the shoot). Rhizomes with attached roots were planted in a 3 peat : 2 pumice $(\mathrm{v} / \mathrm{v})$ growing medium held in 4.5-L (200-mm-diameter) rigid-plastic containers, which were spaced at $\approx 450 \mathrm{~mm}$ centers to minimize mutual shading of plants. The medium was $\approx 170 \mathrm{~mm}$ deep in the containers, which were flat-bottomed and fitted with drainage holes to allow capillary irrigation. Containers were placed in direct contact with a capillary mat $(\approx 7 \mathrm{~mm}$ thick) which was protected with a finely perforated, black plastic sheet to minimize algal growth, and supported on a slightly sloping (1:100) table (Handreck and Black, 1991). The capillary matting was kept constantly wet using tap water having an electrical conductivity of $25 \mathrm{dS} \cdot \mathrm{m}^{-1}$ at $25^{\circ} \mathrm{C}$, and $\mathrm{Ca}$ and $\mathrm{Mg}$ concentrations of 78 and $15 \mathrm{~g} \cdot \mathrm{m}^{-3}$, respectively.

Optimization studies using response surface methodology (Myers and Montgomery, 1995) require specification of an appropriate experimental design in the factors affecting the responses, which in this case were levels of $\mathrm{N}, \mathrm{P}$, and $\mathrm{K}$. We selected a three-factor, second-order central composite design prescribing 16 treatments, with 12 replications totaling 192 plants (one per container). These 16 treatments comprise eight from the $2^{3}$ factorial, two center points, and two extreme points from each of the three dimensions. These were different combinations of five scaled rates $(-2,-1,0,1$, and 2$)$ of $\mathrm{N}, \mathrm{P}$, and $\mathrm{K}$ applied to the growing medium before rhizomes were planted. Table 1 details these combinations, both in scaled and actual elemental levels. The 12 replications comprised three blocks (main plots), each containing four strata (subplots) based on rhizome size classes, arranged randomly within each block. Each stratum contained a single replication of 16 treatments, with containers (sub-subplots) arranged randomly within each stratum.

Nitrogen was supplied as $39 \mathrm{~N}-0 \mathrm{P}-0 \mathrm{~K}$ in the form of a 5 to 6 month controlled-release urea fertilizer (Osmocote, Grace Sierra, Heerlen, The Netherlands), $\mathrm{P}$ as single superphosphate (9\% P) (Ravensdown Fertilizer Cooperative, Napier, New Zealand), and $\mathrm{K}$ as potassium sulfate $(45 \% \mathrm{~K})$. The growing medium in all containers was amended with finely divided dolomitic limestone $\left(3.0 \mathrm{~kg} \cdot \mathrm{m}^{-3}\right)$, gypsum $\left(1.0 \mathrm{~kg} \cdot \mathrm{m}^{-3}\right)$, Micromax microelement fertilizer $\left(0.6 \mathrm{~kg} \cdot \mathrm{m}^{-3}\right.$, Smiths Industries, Auckland, New Zealand), and hydrated ferrous sulfate $\left(0.2 \mathrm{~kg} \cdot \mathrm{m}^{-3}\right)$.

For each plant, the days were recorded when the first, second, and third shoots emerged $(>10 \mathrm{~mm})$ above the growing medium, and when flowering of each inflorescence (when the first floral bract to open in the inflorescence had reflexed $>20 \mathrm{~mm}$ at the tip) occurred. At the time of flowering, each flowering shoot (flower) with sheathing leaves was cut at the surface of the growing medium. For each shoot, the number of subtending leaves and total shoot length were recorded, and total leaf blade area and dry weights (following desiccation at $80^{\circ} \mathrm{C}$ for $24 \mathrm{~h}$ ) of inflorescence, peduncle, leaves and sheathing leaf bases (including petioles) were measured. A final destructive harvest was made after 238 days (21 July 1992) when we recorded the number of emerged shoots remaining on each plant, leaf blade area, and dry weights of leaves, petioles, and sheathing leaf bases. Inflorescences that had not emerged above enclosing leaf bases were noted, as were any shoots with darkened cores. The latter shoots were recorded as having aborted floral development.

Initial analyses of variance were designed to test replications for block and rhizome size effects, and for nutrient main and interaction effects. Thereafter, response surfaces were fitted for each variable using a backward elimination procedure, and examined to determine rates of application which were maximal or minimal for each nutrient. These examinations formed the main focus of the study. Only in the case of total leaf area were block differences significant, and two block dummy variables were incorporated to adjust for these differences. For all other response variables, block differences were nonsignificant, and data were averaged over the three blocks. The smallest rhizome size class was deleted from analyses for continuous response variables having significant amounts of missing data (flowering shoot height, dry weight of inflorescence, number of leaves subtending the inflorescence, time to first flower, and time from first shoot emergence to flowering). There were increasing numbers of missing data points for the times of second and third shoot emergence (11.5\% and $45 \%$, respectively). Sufficient information remained to test for both rhizome size dependence and a full response surface fit in all cases.

Where the response variable was a time duration in days, a 


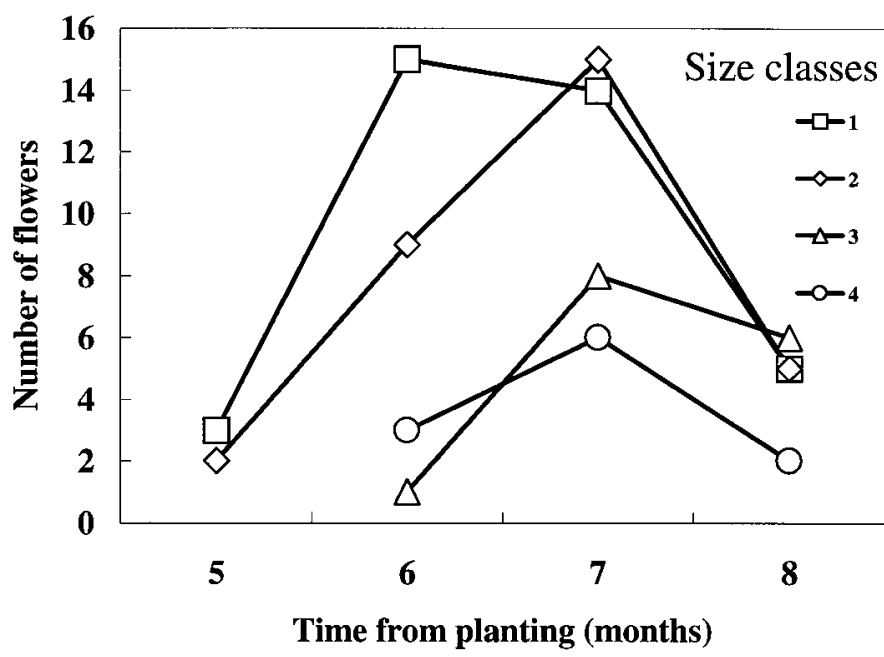

Fig. 1. Number of Heliconia 'Golden Torch' flowers harvested each month for four rhizome size classes $(1,2,3$, and 4 corresponding to $\approx 60,45,30$, and $15 \mathrm{~g}$ fresh weight, respectively). Data are for flowers arising from the first shoots to emerge after planting for the 48 plants in each rhizome size class.

reciprocal transformation was applied, and analyses carried out on the resulting rate response variables. For flower production of first and second shoots, a logit transformation was used to provide examination of the probability of a shoot producing a flower. Both the reciprocal transformation for duration (time) responses and the logit for binary (success/failure) responses are well established procedures in biometric data analysis (Box and Cox, 1994; Steel et al., 1997).

\section{Results}

The comprehensive nature of the experimental design allowed us to explore responses to combinations of treatments that would not be practicable to study in a traditional factorial design. Our results, therefore, relate predominantly to responses obtained from fitted surfaces. For many variables both the size of planted rhizomes and individual mineral nutrients affected timing of development, vegetative growth, and flowering in Heliconia 'Golden Torch'. For others, either rhizome size or individual nutrients affected response. There were no significant interactions between rhizome size and nutrient treatments.

There was a linear, positive effect of rhizome size on timing of plant development events. In general, the larger the rhizome planted, the shorter the time for the first shoot to emerge. Time to emergence of the first shoot ranged from 25 to $41 \mathrm{~d}$ on average as size decreased from the largest to smallest rhizomes (Table 2). As $\mathrm{N}$ rate increased, time to emergence also declined with a minimum predicted to occur at or above the maximum $\mathrm{N}$ rate used in this experiment (Table 2). The fitted surface was given by the following equation: days to emergence $=39.6+5.6 \mathrm{Size}-21.2 \mathrm{~N}$ $-20.5 \mathrm{P}-35.5 \mathrm{~K}+28.3 \mathrm{NK}+48.3 \mathrm{PK}$ (all coefficients significant at $P<0.05$, standard error of the estimate $\pm 11.8 \mathrm{~d}$ ). Examination of this surface reveals that the shortest time to emergence of the first shoot can be expected for high values of $\mathrm{N}$ and $\mathrm{P}$, and low values of $\mathrm{K}$. Within the region covered by the experiment, application rates for $\mathrm{N}, \mathrm{P}$, and $\mathrm{K}$ of $0.9,0.6$ and $0.25 \mathrm{~kg} \cdot \mathrm{m}^{-3}$, respectively, would lead to expected emergence after $17.3 \mathrm{~d}$ for the largest rhizomes.

Time between first shoot emergence and flowering, and from planting to flowering of the first emerging shoot were not signifi- cantly affected by N, P or K. However, as with shoot emergence, there was a significant rhizome size effect on these two variables. The time between emergence and flowering predicted for the largest and second smallest rhizomes (data for the smallest rhizomes having been omitted from analysis) was 156 and $168 \mathrm{~d}$, respectively. Faster emergence and time to flower after emergence meant the largest rhizomes were predicted to flower $\approx 30 \mathrm{~d}$ faster from planting than the second smallest size class $(179 \mathrm{~d}$ or 25 May compared to $210 \mathrm{~d}$ or 25 June, respectively). This was reflected in the number of first shoot inflorescences harvested each month. Over all rhizome size classes, flowering of first shoots to emerge peaked $\approx 6$ months after planting, and declined in the last month before the experiment was terminated (Fig. 1).

Rhizome size influenced the time taken for second and third shoots to emerge, with larger rhizomes showing faster shoot emergence (Table 3). Linear and quadratic $\mathrm{N}$ terms were significant for second shoot emergence, with the fitted surface given by the following equation: Days to Emergence $=0.0119-0.00135 \mathrm{Size}$ $+0.0228 \mathrm{~N}-0.0109 \mathrm{~N}^{2}$ (standard error of the estimate \pm 0.00736 d). This equation indicated a minimum average time to emergence of $49 \mathrm{~d}$ at a $\mathrm{N}$ rate of $1.05 \mathrm{~kg} \cdot \mathrm{m}^{-3}$. To optimize (i.e., minimize) time to shoot emergence for the first three shoots, $\mathrm{N}$, $\mathrm{P}$, and $\mathrm{K}$ application rates of $1.05,0.4$, and $0.5 \mathrm{~kg} \cdot \mathrm{m}^{-3}$, respectively, were predicted. At these rates, expected times between planting and emergence of first, second, and third shoots for rhizomes of average size were 30,49 , and $75 \mathrm{~d}$, respectively.

The number of shoots that emerged per plant during the experiment was unaffected by rhizome size. However, this variable was strongly influenced by mineral nutrition, with significant positive linear effects of $\mathrm{N}, \mathrm{P}$, and $\mathrm{K}$, and quadratic effects of $\mathrm{N}$ and $\mathrm{P}$. There were no significant mineral nutrient interactions. Maximum numbers of shoots to emerge per plant was predicted at $\mathrm{N}$ and $\mathrm{P}$ rates of 1.16 and $0.67 \mathrm{~kg} \cdot \mathrm{m}^{-3}$, respectively, by the following equation: Number of Shoots $=0.95+8.54 \mathrm{~N}$ $+5.95 \mathrm{P}-3.67 \mathrm{~N}^{2}-4.5 \mathrm{P}^{2}$ (standard error of the estimate \pm 1.7 shoots) (Fig. 2). Increasing $\mathrm{K}$ from 0 to $1.0 \mathrm{~kg} \cdot \mathrm{m}^{-3}$ increased the predicted maximum by 0.34 shoots per plant for each $0.25 \mathrm{~kg} \cdot \mathrm{m}^{-3} \mathrm{~K}$ increase (from 7.85 shoots per plant with no addition of $\mathrm{K}$ ), but did not alter the location of the maximum with respect to $\mathrm{N}$ or $\mathrm{P}$.

Flowering occurred only in the first three shoots to emerge, the proportion of shoots producing flowers declining sharply with order of shoot emergence $(57 \%, 26 \%$, and $7 \%$ over all treatments, respectively). As rhizome size increased, the mean number of flowers produced increased linearly, with about four times as many inflorescences harvested from the largest size than from the smallest size across all nutrient treatments. Averaged across all rhizome sizes, 1.2 flowers per plant were harvested over the whole experimental period. Inflorescences harvested from the

Table 3. Main effect of rhizome size on the observed times from planting to second and third shoot emergence (mean $\pm \mathrm{SE}$ ) in Heliconia 'Golden Torch'.

\begin{tabular}{lcc}
\hline \hline & $\begin{array}{c}\text { Time to } \\
\text { emergence of } \\
\text { second shoot } \\
\text { Rhizome } \\
\text { size }^{\mathrm{z}}\end{array}$ & $\begin{array}{c}\text { Time to } \\
\text { emergence of } \\
\text { third shoot } \\
(\mathrm{d})\end{array}$ \\
\hline 1 (largest); $\mathrm{n}=48$ & $52.3 \pm 3.3$ & $87.8 \pm 14.2$ \\
$2 ; \mathrm{n}=48$ & $54.3 \pm 2.6$ & $103.2 \pm 13.8$ \\
$3 ; \mathrm{n}=48$ & $60.2 \pm 4.2$ & $159.6 \pm 16.7$ \\
4 (smallest); $\mathrm{n}=48$ & $65.7 \pm 4.6$ & $198.0 \pm 17.2$
\end{tabular}

${ }^{\mathrm{z}}$ Rhizomes size classes corresponded to $\approx 60,45,30$, and $15 \mathrm{~g}$ fresh weight. 


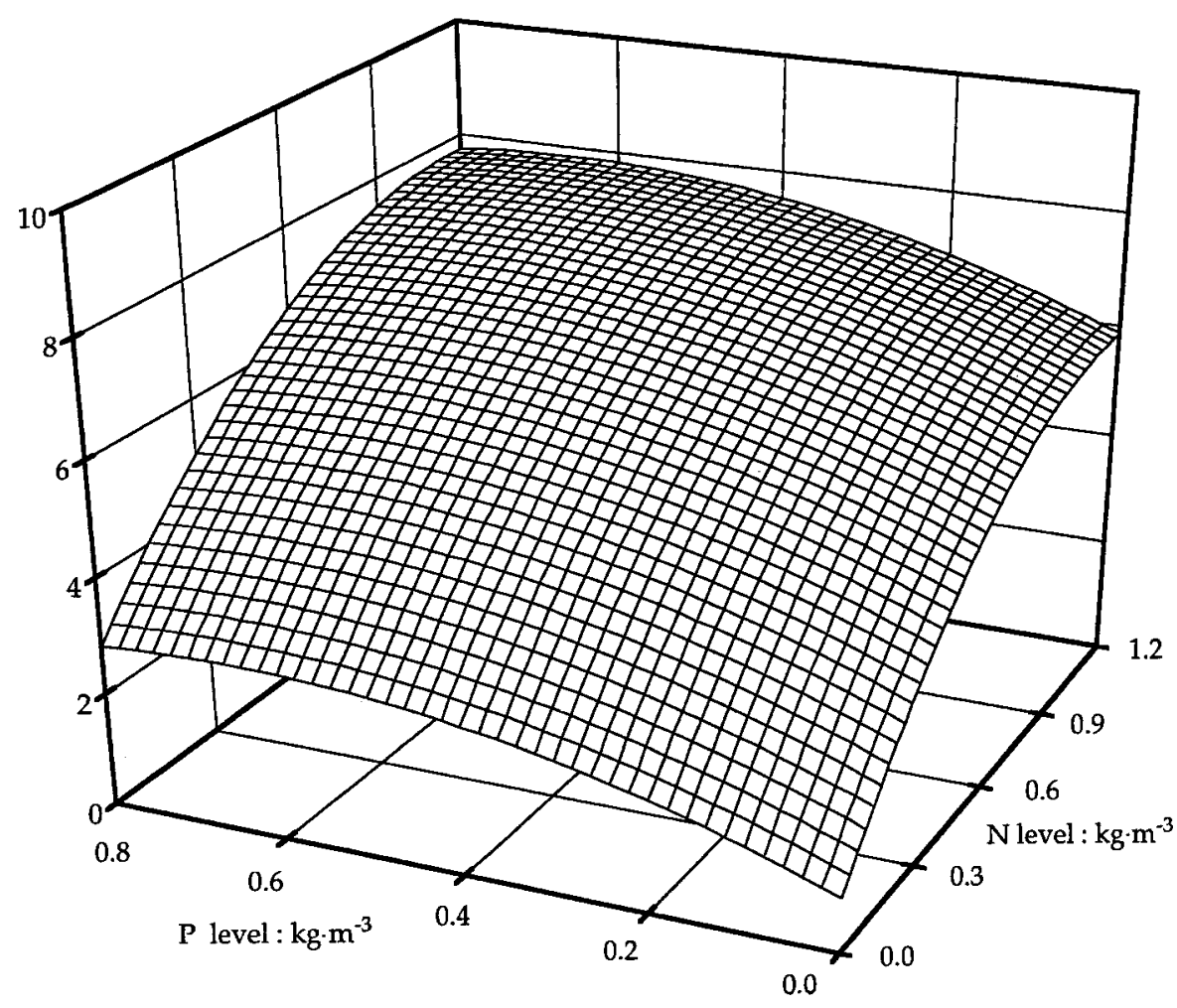

Fig. 2. Predicted number of shoots per plant to emerge in Heliconia 'Golden Torch' during the experiment as a function of $\mathrm{N}$ and $\mathrm{P}$, with no $\mathrm{K}$ addition.

larger rhizomes were heavier, and the proportion of flowers harvested relative to the number of shoots that emerged also increased linearly with size of rhizome planted (Table 4).

Mineral nutrition was also important for these floral attributes as shown by detailed examination of the probabilities of first and second shoots producing flowers (Table 5). The first shoot had a higher probability of flowering than the second shoot, although the difference could be minimized by appropriate choice of $\mathrm{N}, \mathrm{P}$, and K. Likewise, the probability that a rhizome would produce a flower declined with rhizome size (for both first and second shoots to emerge), although this decrease could be ameliorated by appropriate nutrition. Optimization of the probability of flowering over $\mathrm{N}, \mathrm{P}$, and $\mathrm{K}$ was obtained at application rates of 0.98 , 0.02 , and $1.0 \mathrm{~kg} \cdot \mathrm{m}^{-3}$, respectively (Table 5). Because of the small numbers involved, it was not possible to analyze for the effects of rhizome size and nutrition on the rate of floral abortion in the first or second shoots to emerge. The overall probability of floral abortion occurring was $0.125 \pm 0.024$.

A high rate of $\mathrm{N}$ and moderate rates of $\mathrm{P}$ and $\mathrm{K}$ (1.2 or higher, 0.46 and $0.6 \mathrm{~kg} \cdot \mathrm{m}^{-3}$, respectively) were predicted to yield inflorescences with the highest dry weight of $\approx 1.54 \mathrm{~g}$ from the largest rhizome size. Length of flowering shoots was not significantly affected by rhizome size, and there were limited nutrient effects. A shoot length of $\approx 0.7 \mathrm{~m}$ was predicted when $\mathrm{N}, \mathrm{P}$, and $\mathrm{K}$ were applied at rates slightly above those in the middle of the ranges studied.

There were significant linear and negative quadratic terms for $\mathrm{N}, \mathrm{P}$, and $\mathrm{K}$, as well as $\mathrm{N}-\mathrm{P}$ and $\mathrm{P}-\mathrm{K}$ interactions, for the number of leaves subtending each inflorescence on the first shoot to emerge. A maximum of 6.7 to 7.0 leaves was predicted at high rates of $\mathrm{N}$ and $\mathrm{P}\left(>0.9\right.$ and $0.6 \mathrm{~kg} \cdot \mathrm{m}^{-3}$, respectively), from the following equation: Number of Leaves $=5.5+2.5 \mathrm{~N}+0.8 \mathrm{P}+2.7 \mathrm{NP}-2.6 \mathrm{~N}^{2}$ $-2.1 \mathrm{P}^{2}$ (standard error of the estimate \pm 1.9 leaves) (Fig. 3). The position of the maximum shifted to lower $\mathrm{N}$ and $\mathrm{P}$ rates as $\mathrm{K}$ increased. At lower and higher rates of $\mathrm{N}$ and $\mathrm{P}$ application, the number of subtending leaves was predicted to drop to 5 to 6 , especially in response to low $\mathrm{N}$. The number of leaves subtending the inflorescence was not affected by rhizome size.

Dry weight of leaves, all other vegetative aerial parts, and total aerial biomass per plant at final harvest were affected by rhizome size. The largest rhizomes produced the highest values. All vegetative growth variables formed a consistent grouping in that $\mathrm{N}, \mathrm{P}$, and $\mathrm{K}$ were significant, as were downward curvature terms $\mathrm{N}^{2}$ and $\mathrm{P}^{2}$, and the $\mathrm{P} \times \mathrm{K}$ interaction. Maximum production was predicted at $\mathrm{N}, \mathrm{P}$, and $\mathrm{K}$ rates of $\approx 1.2$, 0.5 , and $0.48 \mathrm{~kg} \cdot \mathrm{m}^{-3}$, respectively).

\section{Discussion}

Application rates for $\mathrm{N}, \mathrm{P}$, and $\mathrm{K}$ of $\approx 1.2,0.5$, and $0.63 \mathrm{~kg} \cdot \mathrm{m}^{-3}$, respectively, gave maximal response for a number of variables, including inflorescence weight, leaf area, and all vegetative dry weights. These rates, in the approximate ratio of $2: 1: 1$, are similar to the nutrient regime reported by Broschat et al. (1984). Their $18 \mathrm{~N}-6 \mathrm{P}-12 \mathrm{~K}$ fertilizer at $3 \mathrm{~kg} \cdot \mathrm{m}^{-2} \cdot \mathrm{year}^{-1}$ applied to beds effectively $0.3 \mathrm{~m}$ deep, corresponds to $1.2,0.4$ and $0.8 \mathrm{~kg} \cdot \mathrm{m}^{-3}$ for a period equivalent to our experiment.

A lower ratio of $\approx 1 \mathrm{~N}: 1 \mathrm{~K}$ was predicted to favor both shoot production, and (for first and second shoots at least) the probability of shoots producing flowers. Such ratios are closer to that of 1:2 recommended by van Raalte and van Raalte-Wichers (1973) and others favoring a relatively low ratio of $\mathrm{N}$ to $\mathrm{K}$ (Ball, 1986; Criley, 1990). The apparent inconsistency between fertilizer recommendations in the literature may result from the differing $\mathrm{N}$ to $\mathrm{K}$ ratios and rates required for vegetative growth compared to

Table 4. Main effect of rhizome size on the observed flowering characteristics (mean \pm SE) in Heliconia 'Golden Torch'.

\begin{tabular}{lccc}
\hline \hline $\begin{array}{l}\text { Rhizome } \\
\text { size }\end{array}$ & $\begin{array}{c}\text { Flowers } \\
\text { per plant } \\
\text { (no.) }\end{array}$ & $\begin{array}{c}\text { Flower } \\
\text { dry wt } \\
(\mathrm{g})\end{array}$ & $\begin{array}{c}\text { Proportion of } \\
\text { emerged shoots } \\
\text { flowering }\end{array}$ \\
\hline 1 (largest); $\mathrm{n}=48$ & $1.21 \pm 0.12$ & $0.917 \pm 0.084$ & $0.197 \pm 0.019$ \\
$2 ; \mathrm{n}=48$ & $0.98 \pm 0.12$ & $0.773 \pm 0.091$ & $0.155 \pm 0.020$ \\
$3 ; \mathrm{n}=48$ & $0.48 \pm 0.11$ & $0.340 \pm 0.085$ & $0.064 \pm 0.014$ \\
4 (smallest); $\mathrm{n}=48$ & $0.33 \pm 0.09$ & $0.256 \pm 0.071$ & $0.050 \pm 0.014$ \\
\hline
\end{tabular}

${ }^{\mathrm{z}}$ Rhizomes size classes corresponded to $\approx 60,45,30$, and $15 \mathrm{~g}$ fresh weight. 
Table 5. Estimates of the probabilities of first and second order shoots of Heliconia 'Golden Torch' flowering for four rhizome sizes, using central $\mathrm{N}-\mathrm{P}-\mathrm{K}$ values $\left(0.6,0.4\right.$, and $0.5 \mathrm{~kg} \cdot \mathrm{m}^{-3}$, respectively), and optimizing $\mathrm{N}-\mathrm{P}-\mathrm{K}$ values $\left(0.98,0.02\right.$, and $1.0 \mathrm{~kg} \cdot \mathrm{m}^{-3}$, respectively).

\begin{tabular}{|c|c|c|c|c|}
\hline \multirow{2}{*}{$\begin{array}{l}\text { Rhizome } \\
\text { size }^{z}\end{array}$} & \multicolumn{2}{|c|}{$\begin{array}{c}\text { Central } \\
\mathrm{N}-\mathrm{P}-\mathrm{K} \text { values }\end{array}$} & \multicolumn{2}{|c|}{$\begin{array}{c}\text { Optimizing } \\
\mathrm{N}-\mathrm{P}-\mathrm{K} \text { values }\end{array}$} \\
\hline & Shoot 1 & Shoot 2 & Shoot 1 & Shoot 2 \\
\hline 1 (largest) & 0.99 & 0.40 & 1.00 & 0.98 \\
\hline 2 & 0.96 & 0.33 & 1.00 & 0.96 \\
\hline 3 & 0.73 & 0.15 & 0.99 & 0.92 \\
\hline 4 (smallest) & 0.12 & 0.05 & 0.90 & 0.76 \\
\hline
\end{tabular}

${ }^{\mathrm{z}}$ Rhizomes size classes corresponded to $\approx 60,45,30$, and $15 \mathrm{~g}$ fresh weight.

floral development. Whereas high $\mathrm{N}$ and a high $\mathrm{N}: \mathrm{K}$ ratio favor biomass production (reflected in vegetative growth and size of flowers), a more moderate $\mathrm{N}$ and low $\mathrm{N}: \mathrm{K}$ ratio favor flower production.

The higher flower production and flower weight arising from larger rhizomes was not unexpected because of the greater initial leaf count and carbohydrate reserves one would expect in larger rhizomes. However, although flower production could be maximized with appropriate nutrition at 1.7 flowers per plant over the whole 8 months, this was relatively low compared to that reported for Heliconia 'Golden Torch' by Catley and Brooking (1996). These authors obtained $\approx 2.1$ and 3.0 flowers per plant in 8 months. Both studies used temperatures considered favorable for flower production in Heliconia 'Golden Torch' (or closely related cultivars) (Geertsen, 1989; van Raalte and van RaalteWichers, 1973). Catley and Brooking (1996) grew their plants in controlled-environment rooms at photosynthetic photon fluxes $(P P F)$ of 475 or $710 \mu \mathrm{mol} \cdot \mathrm{m}^{-2} \cdot \mathrm{s}^{-1}$. Using total global solar radiation records for the experimental period, and a light transmittance of $\approx 80 \%$ actually measured in the greenhouse (reduced by the aluminium structure from $93 \%$ for the plastic covering alone), our Heliconia 'Golden Torch' plants were growing at 800 to $900 \mu \mathrm{mol} \cdot \mathrm{m}^{-2} \cdot \mathrm{s}^{-1}$ for only the first 3 months of our experiment. After March, this dropped to $\approx 280$ $\mu \mathrm{mol} \cdot \mathrm{m}^{-2} \cdot \mathrm{s}^{-1}$ from May through July. Based on these considerations, we suggest that under New Zealand conditions, photosynthetically active radiation $(P A R)$ would need to be maintained artificially at or close to summer levels after March to maintain flower production. It is unlikely that daylength extension alone could have helped sustain flower production since Heliconia 'Golden Torch' is insensitive to photoperiod (Broschat et al., 1984).

Under nonshaded conditions in Florida, Broschat et al. (1984) observed an enhancement of flower yield in $H$. psittacorum 'Andromeda' when nutrient status increased from $\approx 0.125 \mathrm{~kg} \cdot \mathrm{m}^{-3}$ for each of $\mathrm{N}, \mathrm{P}$, and $\mathrm{K}$ to $1.05,0.4$, and $0.75 \mathrm{~kg} \cdot \mathrm{m}^{-3}$ for $\mathrm{N}, \mathrm{P}$, and $\mathrm{K}$, respectively. This increase in flower yield with increasing nutrient supply was not observed when $63 \%$ shade was imposed (Broschat et al., 1984). Since we obtained significant increases in flower yield and other growth variables in Heliconia 'Golden Torch' as nutrients were increased between these lower and upper rates (and beyond for $\mathrm{N}$ and $\mathrm{K}$ ), irradiance probably was not limiting in our experiment to the extent of that imposed by $63 \%$ shade in Florida (Broschat et al., 1984).
The first shoots to emerge took a minimum of $\approx 5$ months from emergence (mid-December) to flowering (mid-May). On this time scale, second shoots emerging $\approx 26 \mathrm{~d}$ after the first shoots, should have had ample time to initiate flowers, complete floral development and flower before the final harvest in July. The lower production from the second shoots to emerge may reflect a less favorable light environment for floral initiation, there being no indication that floral abortion rates differed between first and second shoots. As floral initiation is believed to occur during leaf production and expansion (during mid-January to mid-March), a decreasing light integral may have been exerting its effect in early autumn (March) when $P A R$ had declined to $\approx 550 \mu \mathrm{mol} \cdot \mathrm{m}^{-2} \cdot \mathrm{s}^{-1}$.

It is unlikely that competition between shoots for light limited flower production in second and subsequent shoots because flowering shoots were harvested as they reached maturity, and a wide plant spacing was used to minimize mutual plant shading. It is not known if flower and shoot harvesting in itself would have limited flower production in later orders of shoots by limiting the photosynthetic capacity of the plant overall. However, this seems unlikely as harvests would have been made several weeks after later orders of shoots had established their leaf canopies.

Lower flower production in second and higher order shoots may also have been a result of limiting rooting volume. In this regard, it is significant that flower production over 8 months in our experiment and in that of Catley and Brooking (1996) who used 4-L containers ( 1.7 and 2 to 3 flower per plant, respectively) are an order of magnitude lower than that reported for Heliconia 'Golden Torch' by Manarangi et al. (1988).

Number of leaves subtending the inflorescence on the first shoot to emerge was affected by mineral nutrition, the number declining particularly in response to $\mathrm{N}$ rates above and below the predicted maximum (Fig. 3). Maximum number of subtending leaves was about seven, although Broschat et al. (1984) reported

Fig. 3. Predicted number of leaves subtending flowers arising from first shoots to emerge in Heliconia 'Golden Torch' as a function of $\mathrm{N}$ and $\mathrm{P}$, with $\mathrm{K}$ at 0.75 $\mathrm{kg} \cdot \mathrm{m}^{-3}$.

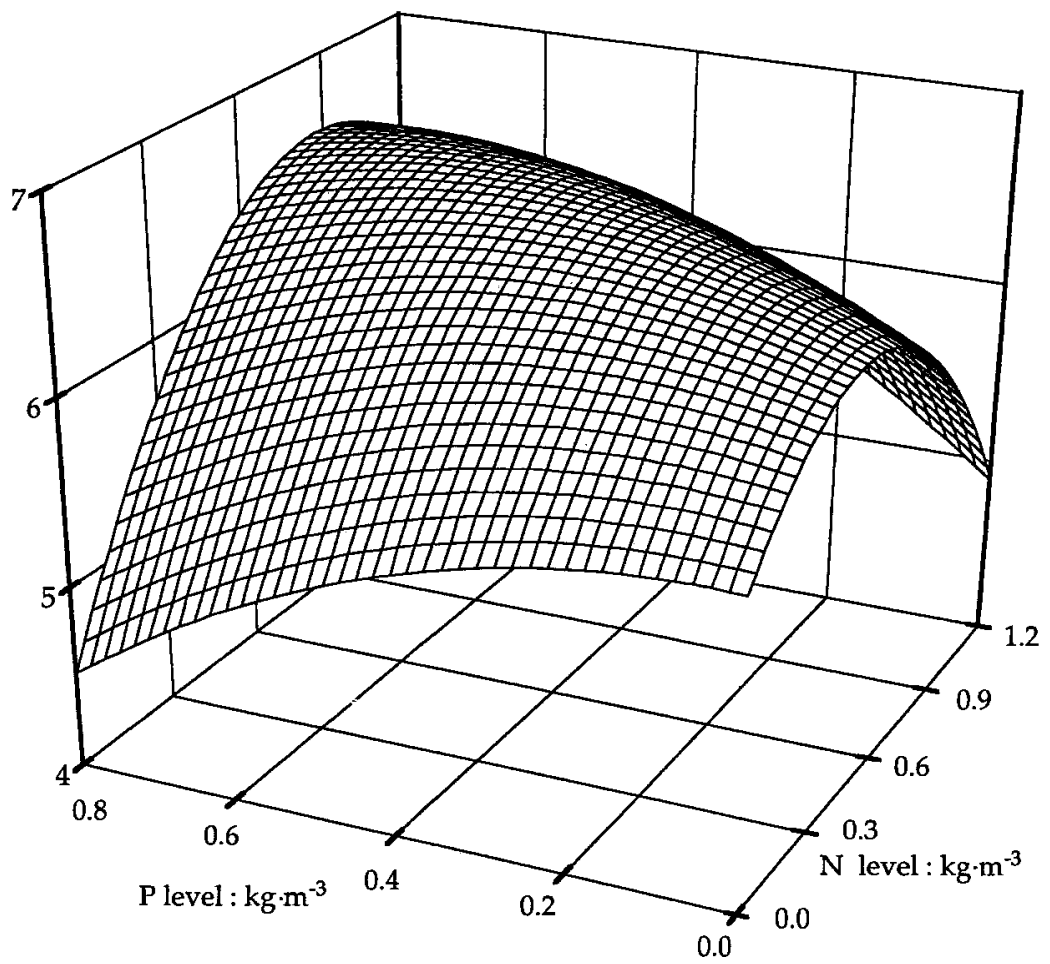


that four to five leaves was typical. Catley and Brooking (1996) found that the number of leaves subtending the inflorescence in Heliconia 'Golden Torch' was lower at their lower temperature, and decreased from a maximum of eight to nine leaves with each successive shoot to emerge. They postulated that a high subtending leaf number could have been due to a delay in floral initiation, perhaps caused by an inadequate carbohydrate supply in the initial propagule. Delay in floral initiation would have resulted in additional leaves developing. However, the effect of nutrition on the number of leaves subtending the inflorescence in our study could not have arisen from a delay in floral initiation because no nutrient factor had an effect on the length of time from shoot emergence to flowering.

We have shown that flower yield in Heliconia 'Golden Torch' can be optimized with appropriate mineral nutrition, with particular attention being paid to the $\mathrm{N}$ to $\mathrm{K}$ ratio so that the size of plants and their flowers is not sacrificed in attempts to increase shoot and flower number. Although N, P, and K were supplied in different release formulations in our study, we minimized nutrient leaching by using capillary irrigation. By using a capillary irrigation system to water container plants, accumulation of nutrients can occur towards the top of a growing medium. However, we do not believe that this was a significant factor in our work. Because of the configuration of the pots and the use of capillary matting rather than flood irrigation, the surface of the growing medium was not noticeably moist. Moreover, a plant canopy rapidly established in each pot, thereby shading the medium surface and reducing evaporation that would have led to ion accumulation. In addition, root systems were ramified throughout the growing medium in each pot. Consequently, the differing effects of the three macroelements on vegetative and reproductive behavior are valid and important findings. The magnitude of nutritional effects in other contexts could be expected to vary depending on growing conditions and methods of nutrient supply and irrigation.

As has been noted by Broschat and Donselman (1983b) and Manrique (1993), flowering in Heliconia sp. grown at high latitudes diminishes during the cooler months with declining light intensity. Commercially successful, year-round production of Heliconia sp. under New Zealand conditions would therefore appear to be unlikely unless substantial light supplementation and heating can be justified. It is more likely that during the warmer and high light intensity months of late spring and summer, greenhouse production under natural illumination could allow profitable production for growers seeking to supply northern hemisphere markets. Plant nutrition as well as rhizome size have important effects on productivity and flower quality attributes at these times of the year. Under favorable conditions it would be important that vigorous cultivars, such as Heliconia X 'Golden Torch', be provided with sufficient rooting volume to overcome within-plant competition.

\section{Literature Cited}

Ball, D. 1986. Rhizome propagation of Heliconia cv. Golden Torch and Heliconia psittacorum cv. Andromeda. Bul. Heliconia Soc. Intl. 1:6-7.

Box, G.E.P. and D.R. Cox. 1994. An analysis of transformations (with discussion). J. Royal Stat. Soc. B 26:211-252.

Broschat, T.K. and H.M. Donselman. 1983a. Production and postharvest culture of Heliconia psittacorum flowers in south Florida. Proc. Fla. State Hort. Soc. 96:272-273.

Broschat, T.K. and H. Donselman. 1983b. Heliconias: A promising new cut flower crop. HortScience 18:2.

Broschat, T.K. and H.M. Donselman. 1987. Tropical cut flower research at the University of Florida's Ft. Lauderdale Research \& Education Center. Bul. Heliconia Soc. Intl. 2:5-6.

Broschat, T.K., H.M. Donselman, and A.A. Will. 1984. 'Andromeda' and 'Golden Torch' heliconias. HortScience 19:736-737.

Catley, J.L. and I.R. Brooking. 1996. Temperature and light influence growth and flower production in Heliconia 'Golden Torch'. HortScience 31:213-217.

Criley, R.A. 1990. Production of heliconias as cut flowers and their potential as new potted plants. Hawaii Coop. Ext. Serv. Hort. Digest, Nursery and Flower Info. No. 92:1-7.

Criley, R.A. and T.K. Broschat. 1992. Heliconia: Botany and horticulture of a new floral crop. Hort. Rev. 14:1-55.

Geertsen, V. 1989. Effect of photoperiod and temperature on the growth and flower production of Heliconia psittacorum 'Tay'. Acta Hort. 252:117-122.

Handreck, K.A. and N.D. Black. 1991. Growing media for ornamental plants and turf. New South Wales Univ. Press, Kensington, NSW, Australia.

Manarangi, A., W.S. Sakai, C. Gerken, M. Crowell, G. Nielson, and R. Short. 1988. Growth and flowering of Heliconia psittacorum cv. Parrot in Hawaii. J. Hawaii Pacific Agr. 1:1-3.

Manrique, L.A. 1993. Greenhouse crops: A review. J. Plant Nutr. 16:2411-2477.

Myers, R.H. and D.C. Montgomery. 1995. Response surface methodology: Process and product optimization using designed experiments. Wiley, New York.

Steel, R.G.D., J.H. Torrie, and D.A. Dickey. 1997. Principles and procedures of statistics: A biometrical approach. 3rd ed. McGraw-Hill, New York.

van Raalte, D. and D. van Raalte-Wichers. 1973. Heliconia. Vakblad voor de Bloemisterij 28:12-13, 15. 